\title{
Spectrophotometric Determination of Bismuth after Collection and Elution of Its Thiourea Complex on Chitin
}

\author{
Suwaru Hoshi, Norikazu Notoya, Masayuki Uto and Mutsuya Matsubara \\ Department of Environmental Engineering, Kitami Institute of Technology, \\ Koen-cho, Kitami 090, Japan
}

Keywords Preconcentration, bismuth-thiourea complex, chitin, spectrophotometry

Various spectrophotometric methods for the determination of bismuth have been developed. ${ }^{1}$ Among those used with various reagents, methods based on the formation of bismuth-thiourea and -iodide colored complexes have been widely used owing to simplicity; the thiourea method has been adopted as the Japanese Industrial Standard method. ${ }^{2}$ However, since the sensitivity of their methods is not sufficient for the determination of low-concentration bismuth in various samples, their spectrophotometric methods for bismuth followed by solvent-extraction techniques have been further developed. ${ }^{3-6}$

We have already proposed both collection-elution and spectrophotometric methods for trace analysis using natural polymer "chitin";, 7 in this process iron and copper (as their 1,10-phenanthroline and neocuproine cationic complexes) were collected on chitin in the presence of suitable anions, and readily eluted with a small volume of eluent.

The bismuth(III)-thiourea cationic complex is also collected in the presence of such anions as dodecyl sulfate and dodecylbenzenesulfonate on chitin, and is easily eluted with a small volume of a $1 \mathrm{M}\left(=\mathrm{mol} / \mathrm{dm}^{3}\right)$ thiourea-methanol solution. In this paper, the spectrophotometric determination of bismuth followed by the collection-elution method on chitin is described.

\section{Experimental}

\section{Reagents and apparatus}

A commercially available chitin powder (Nakarai Tesque) was used without further purification. The atomic absorption standard bismuth solution $(1000 \mu \mathrm{g} /$ $\mathrm{cm}^{3}$, Wako Pure Chemicals) was used, and was further diluted as required. A thiourea (tu) solution (2 M) was prepared by dissolving $76.12 \mathrm{~g}$ of tu (Wako Pure chemicals) in $500 \mathrm{~cm}^{3}$ of water. A dodecyl sulfate (ds) solution $(0.1 \mathrm{M})$ was prepared by dissolving $14.419 \mathrm{~g}$ of sodium dodecyl sulfate (Wako pure Chemicals) in $500 \mathrm{~cm}^{3}$ of water. An eluent was prepared by dissolving
$7.612 \mathrm{~g}$ of tu in $100 \mathrm{~cm}^{3}$ of methanol. Other chemicals used were of analytical grade.

All absorbance measurements were made with a Hitachi 200-10 spectrophotometer. A Hitachi 170-10 atomic absorption spectrophotometer was also used for the determination of bismuth in the eluent.

\section{Standard procedure}

To a solution containing up to $40 \mu \mathrm{g}$ of bismuth, add $1 \mathrm{~cm}^{3}$ of $5 \mathrm{M}$ nitric acid, $10 \mathrm{~cm}^{3}$ of $2 \mathrm{M}$ tu and $2 \mathrm{~cm}^{3}$ of $0.1 \mathrm{M}$ ds; the solution is then diluted with water in a $100 \mathrm{~cm}^{3}$ volumetric flask. Then pass the solution through a chitin column (polyethylene column, $9 \mathrm{~mm}$ i.d. $\times 60 \mathrm{~mm}$ long, $0.2 \mathrm{~g}$ of chitin) at a flow-rate of $20 \mathrm{~cm}^{3} /$ min. Elute the bismuth-tu complex from chitin with $5 \mathrm{~cm}^{3}$ of $1 \mathrm{M}$ tu-methanol, and measure the absorbance of the eluent at $470 \mathrm{~nm}$.

\section{Results and Discussion}

\section{Absorption spectra}

The absorption spectra of the bismuth(III)-tu-ds complex and the reagent blank in the eluent measured against water are shown in Fig. 1. The bismuth complex has an absorption maximum at $470 \mathrm{~nm}$, where the absorbance of the reagent blank is negligible. All absorbance measurements were carried out at $470 \mathrm{~nm}$ in this study.

\section{Condition concerning the collection and elution of the} bismuth complex

The effect of the acid concentration on the collection of the bismuth complex was examined. A maximum, constant absorbance was obtained over the concentration range from 0.005 to $0.1 \mathrm{M}$ of nitric acid in the presence of ds; the bismuth complex could not be collected in the absence of ds. It was supposed that the bismuth complex was collected as its ion-pair complex on chitin. The use of perchloric and hydrofluoric acids instead of nitric acid gave similar results. A $0.05 \mathrm{M}$ nitric acid 


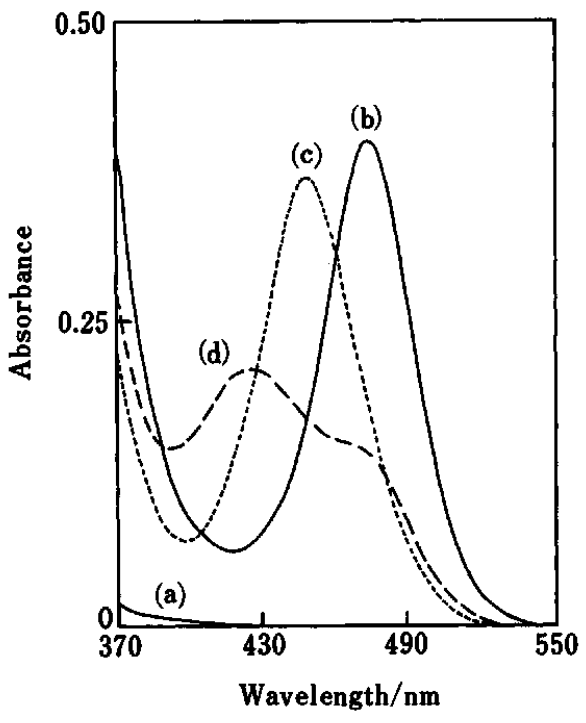

Fig. 1 Absorption spectra of a reagent blank and a bismuthtu complex in an eluent. Condition as standard procedure for $40 \mu \mathrm{g}$ of bismuth: (a) reagent blank; (b) bismuth-tu complex; (c) in the presence of $\mathrm{Cl}^{-}\left(3 \times 10^{-2} \mathrm{M}\right)$; (d) in the presence of $\mathrm{SO}_{4}{ }^{2-}\left(3 \times 10^{-2} \mathrm{M}\right)$; (all reference: water).

concentration is recommended.

The effect of the tu concentration on the collection was examined for a solution containing $40 \mu \mathrm{g}$ of bismuth by using $2 \mathrm{M}$ of a tu aqueous solution. A maximum, constant absorbance of the eluent was obtained over $1 \mathrm{~cm}^{3}$ of a tu solution. In this study, $10 \mathrm{~cm}^{3}$ of a $2 \mathrm{M}$ tu solution was used.

Various counter-ions were tried; the results are shown in Fig. 2. The bismuth complex was collected on chitin in the presence of ds, dodecylbenzenesulfonate (dbs), tetradecanesulfonate $\left(\mathrm{C}_{14}\right)$,dodecanesulfonate $\left(\mathrm{C}_{12}\right)$ and decanesulfonate $\left(\mathrm{C}_{10}\right)$ ions, while 1-octanesulfonate $\left(\mathrm{C}_{8}\right)$, 1-naphthalenesulfonate (1-ns), perchlorate and tetraphenylborate (TPB) ions were ineffective. In this study, ds was mainly used, since its solubility is relatively high in water. As shown in Fig. 2, the maximum, constant absorbance is obtained over a narrow concentration range of ds. The sample solution before being passed through a chitin column was prepared using a volumetric flask; ds was then added to make a $2 \times 10^{-3} \mathrm{M}$ solution. Thus, the reproducibility of the absorbance in the eluent was improved.

The elution of the bismuth complex retained on chitin was tested using methanol, acetone and $N, N$-dimethylformamide as eluents. The bismuth complex decomposed rapidly, even though it was completely eluted with these solvents. The addition of tu to the solvents held down the decomposition rate of the bismuth complex and improved the reproducibilities regarding absorbance in the eluents. Tu-methanol and its aqueous solution were also examined as eluents, since the solubility of tu is high in methanol. Figure 3 shows the elution behavior of the bismuth complex with a

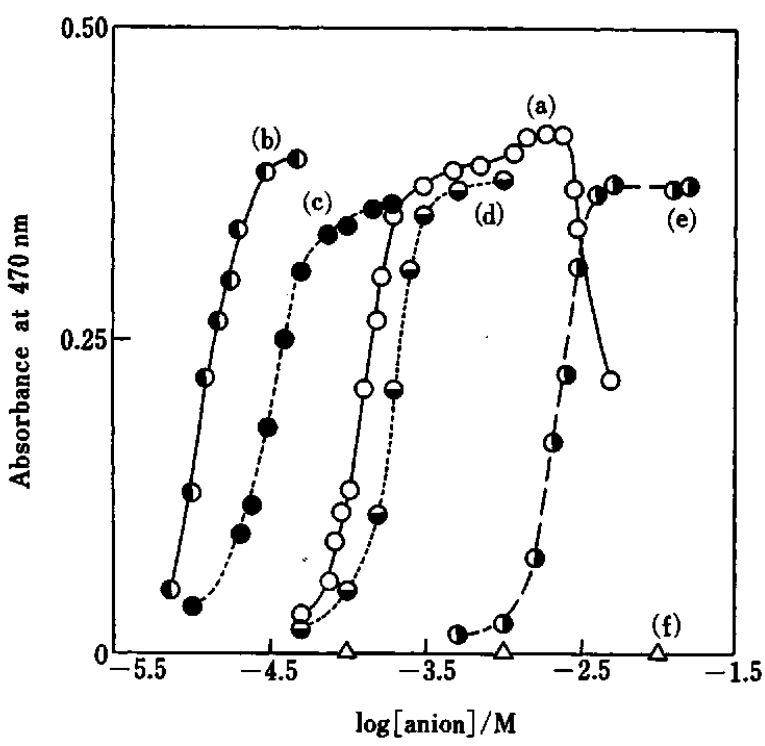

Fig. 2 Effect of the counter ion concentration on collection. Condition as the standard procedure for $40 \mu \mathrm{g}$ of bismuth, except for the counter ion concentration: (a) ds; (b) $\mathrm{C}_{14}$; (c) dbs; (d) $\mathrm{C}_{12}$; (e) $\mathrm{C}_{10}$; (f) $\mathrm{C}_{8}, 1-\mathrm{ns}, \mathrm{ClO}_{4}{ }^{-}$and TPB.

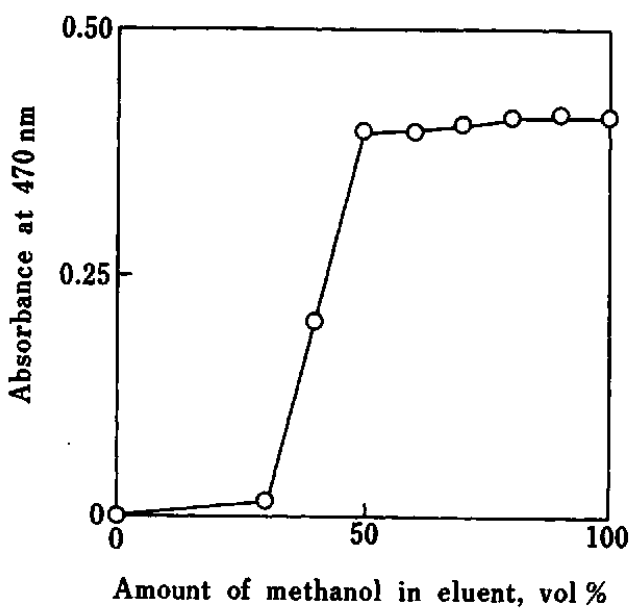

Fig. 3 Elution dependence of the bismuth-tu complex from chitin on methanol concentration in eluent $\left(5 \mathrm{~cm}^{3}\right)$. Each solution contains $1 \mathrm{M}$ tu. Condition as the standard procedure for $40 \mu \mathrm{g}$ of bismuth.

mixture of $1 \mathrm{M}$ tu-methanol-1 $\mathrm{M}$ tu in aqueous solution. The bismuth complex was almost completely eluted with up to $50(\mathrm{v} / \mathrm{v}) \%$ of methanol. Then, $1 \mathrm{M}$ tu-methanol was used as an eluent since its solution could be simply prepared. The absorbance of the eluent, thus obtained, was constant for $24 \mathrm{~h}$.

The flow rate for the collection step was varied from 5 to $50 \mathrm{~cm}^{3}$ (with forced flow when the flow rate was more than $10 \mathrm{~cm}^{3} / \mathrm{min}$ ). Collection of the bismuth complex was complete for a flow rate of up to $40 \mathrm{~cm}^{3} / \mathrm{min}$. The bismuth complex retained was readily eluted with $5 \mathrm{~cm}^{3}$ of eluent within $1 \mathrm{~min}$. 


\section{Calibration, precision and other parameters}

The calibration curve obtained by the standard procedure was linear over the concentration range 5 to $40 \mu \mathrm{g}$ of bismuth in $5 \mathrm{~cm}^{3}$ of eluent. The molar absorptivity was $11000 \mathrm{dm}^{3} \mathrm{~mol}^{-1} \mathrm{~cm}^{-1}$. The relative standard deviation was $1.0 \%$ for $20 \mu \mathrm{g}$ of bismuth (10 measurements).

Collection from $100 \mathrm{~cm}^{3}$ of solution containing $40 \mu \mathrm{g}$ of bismuth on a column with various amounts ( 0.05 to $0.3 \mathrm{~g}$ ) of chitin was examined. The bismuth complex was quantitatively collected on a column containing up to $0.15 \mathrm{~g}$ of chitin.

Recoveries of bismuth $(40 \mu \mathrm{g})$ from various volumes ( 50 to $500 \mathrm{~cm}^{3}$ ) of solution were found to be constant over this range of sample volumes. Up to a 100-fold concentration could be easily achieved.

Ten successive collections on the same chitin were also examined by repeating $1 \mathrm{M}$ nitric acid-water washing cycles. The absorbance of an eluent containing $40 \mu \mathrm{g}$ of bismuth gave almost identical results.

\section{Composition of the ion-pair complex retained on chitin}

The molar ratio of the ion-pair of the bismuth(III)-tu complex with the anions $\left(A^{-}\right)$retained on chitin was investigated using an approach similar to that used in a study concerning solvent extraction.

The collection reaction of the ion-pair complex and distribution ratio $(D)$ between the aqueous phase $(V$, $\left.100 \mathrm{~cm}^{3}\right)$ and the chitin phase $(W, 0.2 \mathrm{~g})$ were defined according to the following equations:

$$
\mathrm{Bi}(\mathrm{tu})_{n}{ }^{3+}+m \mathrm{~A}^{-} \stackrel{K}{\rightleftharpoons} \mathrm{Bi}(\mathrm{tu})_{n}{ }^{3+\cdot} \cdot\left(\mathrm{A}^{-}\right)_{m, \mathrm{~s}}
$$

and

$$
D=\left[\mathrm{Bi}(\mathrm{tu})_{n}{ }^{3+\cdot} \cdot\left(\mathrm{A}^{-}\right)_{m}\right]_{s} /\left[\mathrm{Bi}(\mathrm{tu})_{n}{ }^{3+}\right]=\left(c_{s} / c_{\mathrm{i}}-c_{s}\right)(V / W)
$$

By combining Eqs. (1) and (2),

$$
\log D=\log K+m \log \left[\mathrm{A}^{-}\right]
$$

where subscript $\mathbf{s}$ denotes the chitin phase and $c_{\mathrm{i}}$ is the initial amount $(\mu \mathrm{g})$ of bismuth; $c_{\mathrm{i}}-c_{\mathrm{s}}$ and $c_{\mathrm{s}}$ are the amount of bismuth in the aqueous and chitin phases after being passed through a column, respectively. The distribution data was calculated using the experimental data when the solution was passed through a chitin column at a flow rate of $10 \mathrm{~cm}^{3} / \mathrm{min}$. It was assumed that the amount of bismuth in the chitin phase was the same as that in the eluent. A plot of $\log D$ against $\log \left[\mathrm{A}^{-}\right]$in Eq. (3) gave a straight line having a slope of about 3 (Fig. 4). It was concluded that the composition of the ion-pair complex was $1: 3,\left[\mathrm{Bi}(\mathrm{tu})_{n} \cdot(\mathrm{A})_{3}\right]$. The molar ratio of bismuth to tu was not determined, since an eluent containing tu was used. It seems that the composition of the bismuth-tu complex is $1: 2,\left[\mathrm{Bi}(\mathrm{tu})_{2}{ }^{3+}\right]$, since both its absorption maximum and the molar absorptivity are similar to that found in a study of this

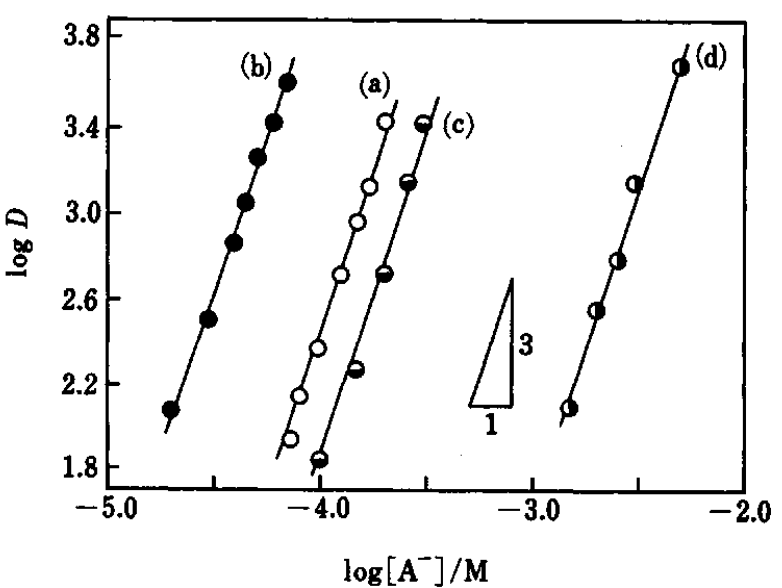

Fig. 4 Plots of $\log D$ vs. $\log$ [anion]. Condition as the standard procedure for $40 \mu \mathrm{g}\left(1.91 \times 10^{-6} \mathrm{M}\right)$ of bismuth by passing through a chitin column at a flow rate of $10 \mathrm{~cm}^{3} / \mathrm{min}$ : (a) ds; (b) dbs; (c) $\mathrm{C}_{12}$; (d) $\mathrm{C}_{10}$.

Table 1 Effect of diverse ions

\begin{tabular}{clcc}
\hline Ions & Added as & Added $/ \mu \mathrm{g}$ & Recovery,\% \\
\hline $\mathrm{Pd}(\mathrm{II})$ & $\mathrm{PdCl}_{2}$ & 20 & 101.0 \\
& & 40 & 111.9 \\
$\mathrm{Ru}(\mathrm{III})$ & $\mathrm{RuCl}_{3}$ & 20 & 100.9 \\
& & 50 & 109.8 \\
$\mathrm{Au}(\mathrm{III})$ & $\mathrm{NaAuCl}_{4}$ & 1000 & 98.0 \\
$\mathrm{Sb}(\mathrm{III})$ & $\mathrm{SbCl}_{3}$ & 1000 & 98.6 \\
\hline
\end{tabular}

Bi taken, $20 \mu \mathrm{g}$.

$2000 \mu \mathrm{g}$ of $\mathrm{Cr}(\mathrm{III}), \mathrm{Mn}$ (II), $\mathrm{Fe}$ (III), $\mathrm{Co}$ (II), Ni(II), $\mathrm{Cu}$ (II), $\mathrm{Zn}(\mathrm{II}), \mathrm{Cd}(\mathrm{II}), \mathrm{Pb}(\mathrm{II}), \mathrm{Sn}(\mathrm{II}), \mathrm{V}(\mathrm{V}), \mathrm{Mo}(\mathrm{V} 1), \mathrm{Ag}(\mathrm{I}), \mathrm{Pt}(\mathrm{II})$, Rh(III), Ir(III), Os(VIII), As(III) and As(V) did not interfere.

system by Hayashi et $a l .^{4}$

\section{Effect of diverse ions}

Table 1 shows the effect of diverse ions on the determination of bismuth. The tolerance limit was taken as being the amount causing an error $\pm 3 \%$ in the absorbance of the eluent for only bismuth. For the determination of $20 \mu \mathrm{g}$ of bismuth, $\mathrm{Cr}$ (III), Mn(II), $\mathrm{Fe}(\mathrm{III}), \mathrm{Co}(\mathrm{II}), \mathrm{Ni}(\mathrm{II}), \mathrm{Cu}(\mathrm{II}), \mathrm{Zn}(\mathrm{II}), \mathrm{Cd}(\mathrm{II}), \mathrm{Pb}(\mathrm{II})$, Sn(II), V(V), Mo(VI), Ag(I), Pt(II), Rh(III), Ir(III), Os(VIII), As(III) and As(V) did not interfere in concentrations up to 100 times that of bismuth. Of these, the metal ions absorbed in the visible region, themselves, may interfere at higher concentrations. Au(III) and $\mathrm{Sb}$ (III) did not interfere at concentrations up to 50 times, but gave a negative error more than the its concentration range due to a competitive reaction with tu. Both Pd(II) and Ru(III), which reacted with tu to form colored complexes, were tolerated only up to equal amounts of bismuth. Among the anions examined, 
Table 2 Recovery of bismuth from some metal powders

\begin{tabular}{ccccc}
\hline Sample & $\begin{array}{c}\text { Aliquot } \\
\text { taken/ } \\
\mathrm{cm}^{3}\end{array}$ & $\begin{array}{c}\mathrm{Bi} \\
\text { added/ } \\
\mu \mathrm{g}\end{array}$ & $\begin{array}{c}\mathrm{Bi} \\
\text { found/ } \\
\mu \mathrm{g}\end{array}$ & $\begin{array}{c}\text { Recovery } \\
\text { of } \mathrm{Bi}, \\
\%\end{array}$ \\
\hline Iron & 20 & 5 & 4.95 & 99.0 \\
powder & & 10 & 10.15 & 101.5 \\
& & 20 & 20.54 & 102.7 \\
Zinc & 20 & 5 & 5.15 & 102.9 \\
powder & & 10 & 9.95 & 99.5 \\
& & 20 & 20.54 & 102.7 \\
Copper & 20 & 5 & 4.95 & 99.0 \\
powder & & 10 & 10.15 & 101.5 \\
& & 20 & 20.44 & 102.2 \\
Antimony & 10 & 5 & 5.05 & 101.0 \\
powder & & 10 & 10.15 & 101.5 \\
& & 20 & 19.85 & 99.3 \\
Tin & 20 & 5 & 5.05 & 101.0 \\
powder & & 10 & 10.15 & 101.5 \\
& & 20 & 19.46 & 97.3 \\
\hline
\end{tabular}

a. Metal powders (Wako Pure Chemicals).

fluoride, iodide, perchlorate and thiocyanate did not interfere up to $1 \times 10^{-2} \mathrm{M}$ in concentration. Sulfate and chloride, however, which changed the absorption maximum of the bismuth complex (Fig. 1) were tolerated up to $5 \times 10^{-4} \mathrm{M}(1775 \mu \mathrm{g}$ as chloride and $4800 \mu \mathrm{g}$ as sulfate) in concentration. The use of hydrochloric and sulfuric acids must be avoided regarding the decomposition of practical samples with acids.

\section{Recovery test of bismuth}

The proposed method was tested concerning the recovery of bismuth from some metal powders. Their sample solutions were prepared as follows: Take $10 \mathrm{mg}$ of each metal powder in a Teflon beaker and dissolve the samples in $5 \mathrm{~cm}^{3}$ of $5 \mathrm{M}$ nitric acid, $1 \mathrm{~cm}^{3}$ of $5 \mathrm{M}$ hydrofluoric acid and $1 \mathrm{~cm}^{3}$ of $5 \mathrm{M}$ perchloric acid with heating. Dilute each solution to $100 \mathrm{~cm}^{3}$ in a volumetric flask. To an aliquot of each sample solution, add 5, 10 and $20 \mu \mathrm{g}$ of bismuth. The bismuth in each sample solution is determined by the standard procedure. The results obtained are summarized in Table 2; the recovery of bismuth from each sample was satisfactory.

By using the method recommended in this study it is possible to determine trace amounts of bismuth compared with the JIS method ${ }^{2}$ in various samples which decompose under mild conditions (as described above). The degree of interference from diverse ions in the present method is also reduced since colored metal ions which do not react with tu are not collected upon passing through a chitin column. A further investigation concerning the effect of diverse ions in applications to practical samples is required.

\section{References}

1. H. Onishi, "Photometric Determination of Traces of Metals", Forth Edition, Part IIA, Wiley Interscience, New York, 1986.

2. JIS H 1364, "Methods for Determination of Bismuth and Lead in Aluminium Alloy", Japanese Industrial Standards Committee, Tokyo, 1971.

3. F. Aoki and H. Tomioka, Bull. Chem. Soc. Jpn., 38, 1557 (1965).

4. K. Hayashi, Y. Sasaki, S. Tagashira and N. Ikuta, Bunseki Kagaku, 29, 785 (1980).

5. T. Matsuo, J. Shida and T. Sasaki, Bunseki Kagaku, 16, 546 (1967).

6. A. Ghosh, K. S. Patel and R. K. Mishra, Bull. Chem. Soc. Jpn., 62, 3675 (1989).

7. S. Hoshi, M. Yamada, S. Inoue and M. Matsubara, Talanta, 36, 606 (1989).

8. S. Hoshi, Y. Tanaka, S. Inoue and M. Matsubara, Anal. Sci., 5, 471(1989). 